\section{Diabetes education in primary care: a randomized clinical trial}

\section{Educação em diabetes na atenção primária: um ensaio clínico randomizado}

\section{Educación sobre diabetes en la atención primaria: un ensayo clínico aleatorizado}

\author{
Maria de Fatima Ferreira Grillo 1 \\ Cristina Rolim Neumann 1 \\ Suzana Fiore Scain 1 \\ Raquel Farias Rozeno 1 \\ Luis Beloli 1 \\ Tiago Perinetto 1 \\ Jorge Luiz Gross 1 \\ Cristiane Bauermann Leitão 1
}

\begin{abstract}
The aim of the study was to evaluate the effect of a structured group education program administered by a primary care nurse in patients with type 2 diabetes mellitus. The sample included 137 patients with type 2 diabetes mellitus, randomized into two groups: intervention (5-week educational course and reinforcements every 4 months for one year) and control (with no structured diabetes mellitus education) with an evaluation of metabolic control, weight, blood pressure, distress scores, and knowledge on diabetes. There were no differences between the two groups in HbAlc at 4, 8, or 12 months when compared to baseline values. An increase in HbAlc was observed in the control group after adjusting for baseline HbAlc and insulin dose ( $p=0.044$ between groups). Knowledge scores and diabetesrelated distress improved after the intervention. A structured educational program administered to type 2 diabetes mellitus patients seen at a primary care unit improved the knowledge and distress associated with the disease. The results also suggest the prevention of an increase in HbAlc.
\end{abstract}

Diabetes Mellitus; Health Education; Primary Health Care

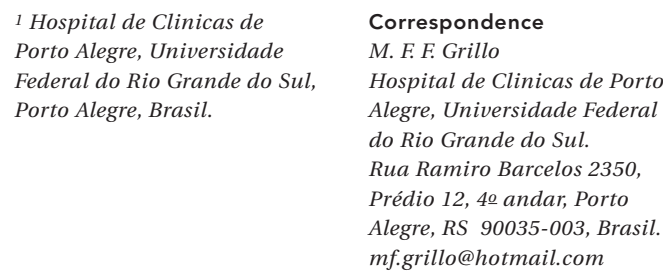

Correspondence M. F. F. Grillo

Hospital de Clinicas de Porto Alegre, Universidade Federal do Rio Grande do Sul. Rua Ramiro Barcelos 2350 Prédio 12, 4o andar, Porto Alegre, RS 90035-003, Brasil. mf.grillo@hotmail.com 


\section{Introduction}

Diabetes mellitus is associated with chronic microvascular (retinopathy, nephropathy, and neuropathy) and macrovascular complications (ischemic heart disease, cerebrovascular disease, and peripheral vascular disease) 1 . Treatment of hyperglycemia decreases the related morbidity and mortality 2 .

Type 2 diabetes mellitus management includes diet, exercise, and medication ${ }^{3}$. Diabetes self-management education has been used to encourage lifestyle changes and improve medication compliance ${ }^{4}$. The efficacy of diabetes mellitus education has been widely accepted, and the certificated diabetes educator (CDE) is considered an important member of the multidisciplinary team responsible for patient care 5,6. However, the efficacy of education in terms of $\mathrm{HbAlc}$ reduction has not been consistently demonstrated. A previous meta-analysis of randomized clinical trials 7 has questioned the benefit of currently available educational programs in decreasing HbAlc in type 2 diabetes mellitus: in fact, only patients with HbAlc greater than $8 \%$ experienced a small improvement (-0.3\%).

We have previously demonstrated the efficacy of a group-based education program ${ }^{8}$ administered by a nurse CDE in a tertiary care university hospital 9 . In 4 months, HbAlc decreased $0.4 \%$ in non-insulin-using type 2 diabetes mellitus patients, but the benefit tended to decrease later, even though it was still significantly different at 12 months.

We hypothesized that an educational program would be more effective in uncontrolled type 2 diabetes mellitus patients attending a primary care outpatient clinic and using the available anti-hyperglycemic agents, including insulin. Moreover, the addition of periodic reinforcement meetings could prolong the expected benefit.

This study thus aimed to evaluate the effect of a group diabetes mellitus education program (a 5-week course and reinforcement meetings every 4 months for one year applied by a generalist nurse) on HbAlc in uncontrolled type 2 diabetes mellitus patients attending a primary care unit.

\section{Material and methods}

\section{Patients}

Subjects were eligible to participate in the trial if they met the following inclusion criteria: adult subjects (between 18 and 80 years old), with type 2 diabetes mellitus and HbAlc $>7 \%$, attend- ing the primary care unit at least once in the 6 months prior to the screening visit, and willing to attend the 5-week course. Exclusion criteria were: history of active infection (e.g. osteomyelitis, pulmonary tuberculosis, AIDS), chronic corticosteroid use, unstable angina or myocardial infarction in the last 3 months, advanced renal disease requiring dialysis, heart failure (New York Heart Association classes III and IV), cirrhosis, alcohol abuse, illicit drug use, dementia, current pregnancy or breastfeeding, current cancer, or any disease that might affect survival in the subsequent 5 years. The protocol was applied at the "Santa Cecília" Primary Care Unit, Hospital de Clínicas de Porto Alegre (Porto Alegre, Rio Grande do Sul State, Brasil). Subjects were enrolled from January 2009 to July 2010, and the last patient concluded the trial in July 2011. Patients received a telephone invitation to participate, and a visit was scheduled to orient them on informed consent and protocol procedures. The protocol was approved by the Ethics Research Committee of the Hospital de Clínicas de Porto Alegre, and all patients provided written informed consent. The study was registered in Clinical Trials (NCT 01473329).

\section{Study design and interventions}

This was a single-center, parallel-group, randomized study. Participants were randomly assigned to the intervention or control group following block randomization procedures. While the course coordinator nurse and patients were aware of the allocated arm, outcome assessors and data analysts were blinded to the allocation.

The intervention group received a structured diabetes self-management education course adapted from Gagliardino et al. ${ }^{8}$. The course consisted of weekly 2-hour meetings for 5 weeks (total duration: 10 hours; 10 participants/group) and reinforcement meetings every 4 months (2 meetings, at months 4 and 8 ) for one year. The course was administered by a generalist nurse trained in diabetes education. The course content included (1) identification of modifiable risk factors for type 2 diabetes mellitus, (2) nonpharmacological treatment, emphasizing diet and exercise, (3) pharmacological therapy, including mechanism of action and side effects of glucose-lowering medications provided by the Brazilian public health system (metformin, glyburide, and NPH and regular insulin), (4) an overview of chronic diabetes complications, and (5) foot care. The control group visited the center at the same frequency as the intervention group, for a diabetic group meeting with the nurse, but no structured diabetes education was provided. 
During the control group meetings, participants discussed personal life issues or those related to other diseases. When control participants asked questions about diabetes, the nurse provided concise answers. Both groups were assisted by the same generalist nurse. All patients received usual medical care at the discretion of their primary care physician.

The primary endpoint was change in HbAlc at 4, 8, and 12 months. Additional analyses evaluated changes in diabetes mellitus literacy, blood pressure, body mass index (BMI), and lipids at the same time-points.

\section{Baseline assessments}

Clinical (age, gender, ethnicity, history of hypertension, blood pressure levels, and smoking status), anthropometrical (weight, height, and waist circumference), and laboratory data (fasting glucose, $\mathrm{HbAlc}$, and lipid profile) were assessed. Ethnicity was self-declared. Blood pressure was measured twice with a digital sphygmomanometer (ONROM, São Paulo, Brazil), with the patient in sitting position, after a 5-min rest and with 1-min interval between measurements. Hypertension was defined as at least two blood pressure measurements $\geq 140 / 90 \mathrm{mmHg}$ on two occasions, or use of antihypertensive medication. Waist circumference was measured midway between the iliac crest and the inferior costal border. BMI (weight/height2) was calculated. Diabetes knowledge was measured with a 22 -item questionnaire addressing the information discussed in the meetings, and will be referred to here as type 2 diabetes mellitus knowledge score. This score correlated with improvements in HbAlc in a previous study ${ }^{9}$. Individuals with higher scores are considered to have more knowledge of diabetes mellitus. The questionnaire was applied at baseline, after the educational course (5 weeks), and at the end of the study (12 months). Physical activity was assessed with the International Physical Activity Questionnaire (IPAQ): and individuals were classified as highly active, minimally active, or inactive (sedentary) 10. Psychological impact of diabetes mellitus was evaluated by the 20-item Problem Areas in Diabetes (PAID) questionnaire 11, with scores varying from 0 to 100; a higher score means greater impact of diabetes mellitus on the patient's life. The IPAQ was applied at baseline and months 4,8 , and 12 , and the PAID questionnaire at baseline and 12 months.

\section{Laboratory findings}

Fasting plasma glucose was measured by the glucose-peroxidase enzymatic colorimetric method
(Bio Diagnóstica, Belém, Brazil) 12. HbAlc measurements were performed by high-performance liquid chromatography - HPLC (Merck-Hitachi 9000, reference range: 4.7-6.0\%, Hercules, USA) 13. Total cholesterol, HDL, and triglycerides were measured by the enzymatic colorimetric method. Low-density lipoprotein cholesterol (LDL) was calculated by the Friedewald formula $[\mathrm{LDL}=$ total cholesterol - (HDL + triglycerides/5)] 14. Dyslipidemia was defined as LDL-cholesterol $\geq 100 \mathrm{mg} / \mathrm{dL}$ and/or HDL-cholesterol $<40 \mathrm{mg} / \mathrm{dL}$ in men and $<50 \mathrm{mg} / \mathrm{dL}$ in woman and/or triglycerides $\geq 150 \mathrm{mg} / \mathrm{dL}$, or use of statins.

\section{Statistical analysis}

Continuous variables are presented as mean \pm standard deviation, median (inter-quartile interval), and categorical variables as absolute number and relative frequency (percentage). Student's t-test and chi-square test were used to compare baseline continuous and categorical variables, respectively. Variables with non-normal distribution were log-transformed. General linear model (GLM) for repeated measurements was used to analyze changes in the outcomes during the trial. HbAlc values after the intervention were adjusted to baseline HbAlc and for possible changes in medication during the trial (doses of metformin, glyburide, and insulin/kg/day; when patients were not on one of these medications, they were not excluded from the analysis, but the dose was considered equal to zero) by multivariate analysis of covariance (MANCOVA). All patients with at least one HbAlc measurement available after randomization were included in the analyses, regardless of whether they attended all the meetings in the educational course (intention-to-treat analysis). A sample of 136 patients (68 in each group) was required to detect a $0.5 \%$ difference in HbAlc, considering the repeat measurement design (baseline and 3 times during the follow-up), $80 \%$ power, and 5\% alpha error. Statistical significance was set at $\mathrm{p}$ $<0.05$ (two-tailed). IBM SPSS 18.0 (IBM Corp., Armonk, USA) and Stata (StataCorp LP, College Station, USA) were used for the analyses.

\section{Results}

\section{Baseline characteristics}

A total of 1,200 type 2 diabetes mellitus patients were registered at the Primary Care Unit and were evaluated for inclusion. Inclusion and exclusion criteria were reviewed on patient charts. Of these patients, 138 were eligible, and one was excluded 
because of amaurosis and difficulties in following protocol procedures. A total of 137 patients agreed to participate in the study. Participants' mean age was $62.4 \pm 9.8$ years and diabetes mellitus duration was $10 \pm 7.8$ years. Fifty patients were male (37\%) and 119 were white (87\%). Mean BMI was $30.3 \pm 5.8 \mathrm{~kg} / \mathrm{m}^{2}$, and subjects had a mean of $8.8 \pm 4.2$ years of schooling. Mean baseline HbAlc was $8.98 \pm 1.92 \%, 125$ (91\%) subjects had hypertension, and 108 (79\%) had dyslipidemia. Table 1 shows the baseline clinical and laboratory characteristics of patients according to randomization group. The intervention and control groups were similar for all the clinical and laboratory variables.

At the end of the trial, 127 (93\%) patients had at least one HbAlc value available after random- ization, and these data were analyzed (Figure 1). Reasons for loss to follow-up ( $\mathrm{n}=10 ; 7 \%$ ) were withdrawal of consent $(n=8)$ and death $(n=2)$. The drop-out patients did not differ from those who completed the trial regarding age, diabetes mellitus duration, proportion of females, ethnicity, and baseline HbAlc (data not shown).

\section{Follow-up results}

The doses of oral anti-hyperglycemic medications did not change from baseline to the end of the study (metformin - intervention group: $1,847 \pm 876 \mathrm{mg}$ vs. $1,841 \pm 961 \mathrm{mg}$, control group: $1,705 \pm 900 \mathrm{mg}$ vs. $1,630 \pm 1,000 \mathrm{mg}$; within-subjects $\mathrm{p}$-value $=0.456$ and between-groups $\mathrm{p}$-value $=$ 0.269 ; glyburide - intervention: $6 \pm 8 \mathrm{mg}$ vs. $7 \pm 8 \mathrm{mg}$,

Table 1

Baseline clinical and laboratory characteristics of patients in the intervention and control groups in a study on diabetes education in Porto Alegre, Rio Grande do Sul State, Brazil.

\begin{tabular}{|c|c|c|c|}
\hline & Educational course $(n=69)$ & Control $(n=68)$ & p-value \\
\hline Age (years) [mean $\pm S D]$ & $61.7 \pm 9.9$ & $63.2 \pm 9.7$ & 0.362 \\
\hline Diabetes mellitus duration (years) [mean $\pm \mathrm{SD}]$ & $10.1 \pm 8.3$ & $9.7 \pm 7.3$ & 0.735 \\
\hline Male [n (\%)] & $20(29)$ & $30(44)$ & 0.097 \\
\hline White $[\mathrm{n}(\%)]$ & $60(87)$ & $59(87)$ & 0.324 \\
\hline $\mathrm{BMI}\left(\mathrm{kg} / \mathrm{m}^{2}\right)[$ mean $\pm \mathrm{SD}]$ & $30.7 \pm 5.7$ & $29.9 \pm 5.8$ & 0.412 \\
\hline Waist circumference $(\mathrm{cm})[$ mean $\pm S D]$ & $105 \pm 13.0$ & $103.4 \pm 12.3$ & 0.913 \\
\hline Hypertension [n (\%)] & $63(91.3)$ & $62(91.2)$ & 1.000 \\
\hline Dyslipidemia [n (\%)] & $57(82.6)$ & $51(75.0)$ & 0.378 \\
\hline Smoking [n (\%)] & $15(21.7)$ & $10(14.7)$ & 0.398 \\
\hline Sedentary [n (\%)] & $56(84)$ & $53(88)$ & 0.440 \\
\hline Schooling (years) [mean \pm SD] & $8.6 \pm 4.4$ & $8.9 \pm 4.0$ & 0.630 \\
\hline Diabetes mellitus knowledge score * [mean $\pm \mathrm{SD}]$ & $12.2 \pm 4.1$ & $12.1 \pm 3.1$ & 0.842 \\
\hline Systolic blood pressure $(\mathrm{mmHg})[$ mean $\pm \mathrm{SD}]$ & $141 \pm 19$ & $141 \pm 18$ & 0.983 \\
\hline Diastolic blood pressure $(\mathrm{mmHg})[$ mean $\pm \mathrm{SD}]$ & $81 \pm 12$ & $81 \pm 11$ & 0.898 \\
\hline Fasting glucose $(\mathrm{mg} / \mathrm{dL})[$ mean $\pm \mathrm{SD}]$ & $164 \pm 76$ & $171 \pm 61$ & 0.562 \\
\hline $\mathrm{HbA} 1 \mathrm{c}(\%)[$ mean $\pm \mathrm{SD}]$ & $8.8 \pm 1.9$ & $9.1 \pm 2.0$ & 0.355 \\
\hline Cholesterol (mg/dL) [mean $\pm S D]$ & $186 \pm 44$ & $186 \pm 42$ & 0.928 \\
\hline $\mathrm{HDL}-\mathrm{c}(\mathrm{mg} / \mathrm{dL})[\mathrm{mean} \pm \mathrm{SD}]$ & $43 \pm 12$ & $48 \pm 16$ & 0.051 \\
\hline $\mathrm{LDL}-\mathrm{c}(\mathrm{mg} / \mathrm{dL})[$ mean $\pm \mathrm{SD}]$ & $108 \pm 37$ & $105 \pm 34$ & 0.591 \\
\hline Triglycerides (mg/dL) [median (interquartile interval)] & $150(118-217)$ & $167(102-206)$ & 0.711 \\
\hline Diabetes mellitus treatment [n (\%)] & & & 0.875 \\
\hline Oral agents & $40(58)$ & $42(62)$ & \\
\hline Oral agents and insulin & $25(36)$ & $23(34)$ & \\
\hline Insulin alone & $4(6)$ & $3(4)$ & \\
\hline PAID score $[$ mean \pm SD] & $20 \pm 14$ & $16 \pm 13$ & 0.154 \\
\hline
\end{tabular}

BMI: body mass index; PAID: Problem Areas in Diabetes.

* 22 questions.

Note: results are presented as the mean \pm standard deviation [mean $\pm \mathrm{SD}$ ], number of subjects with the characteristic [n (\%)],

and median (interquartile interval) [median (interquartile interval)]. 


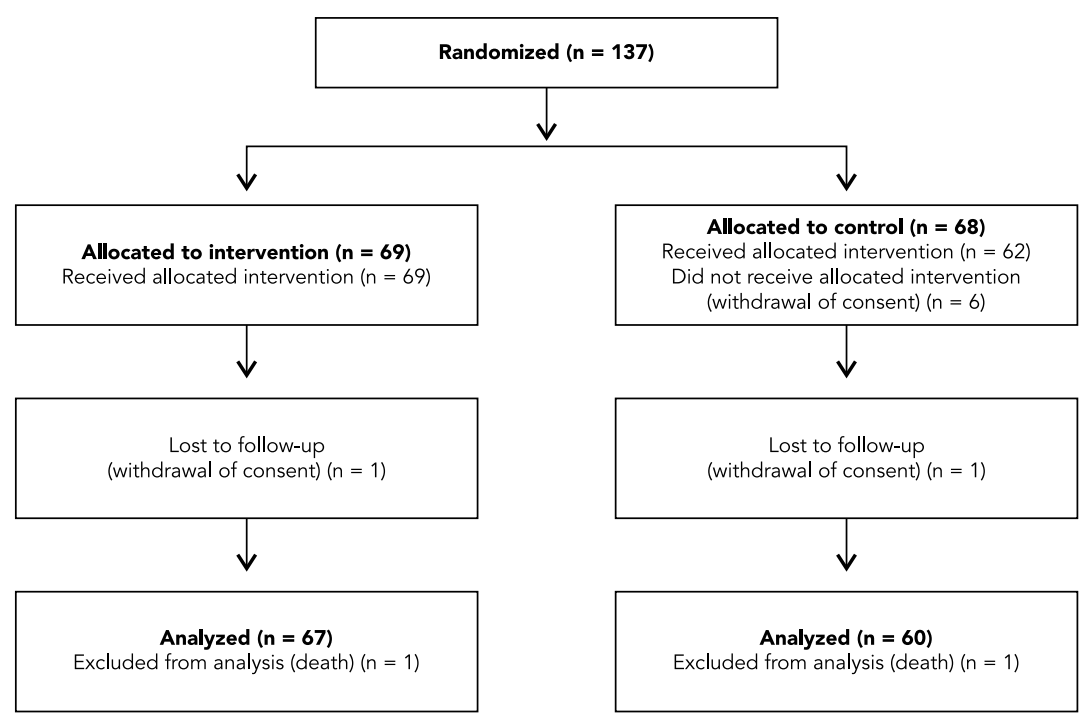

controls: $9 \pm 9 \mathrm{mg}$ vs. $9 \pm 9 \mathrm{mg}$; within-subjects $\mathrm{p}$-value $=0.322$ and between-groups $\mathrm{p}$-value $=$ 0.126). However, there was a similar increment in insulin doses in both groups (intervention: $0.19 \pm 0.31$ vs. $0.24 \pm 0.37 \mathrm{UI} / \mathrm{kg}$, control: $0.15 \pm 0.31$ vs. $0.21 \pm 0.36 \mathrm{UI} / \mathrm{kg}$; within-subjects p-value $<0.001$ and between-groups $p$-value $=0.597$ ). The proportion of patients starting insulin appeared to be higher in the control group (intervention: $7 \%$ vs. controls: $10 \%$ ), but without statistical significance $(\mathrm{p}=0.56)$.

The score on type 2 diabetes mellitus knowledge increased in both groups, with a higher increase in the intervention group (intervention - baseline: $12 \pm 4.0$ vs. after 5 -week: $15 \pm 3$ vs. 12-month: $16 \pm 3$; controls - baseline: $12 \pm 3$ vs. after 5-week: $13 \pm 3$ vs. 12 -month: $12 \pm 4$, withinsubjects $\mathrm{p}$-value $<0.001$ and between-groups $\mathrm{p}$ value $<0.001$ (Figure 2a).

Figure 2b shows the variation in HbAlc during follow-up. In the intervention group, HbAlc was stable during the 12-month follow-up (baseline: $8.8 \pm 1.9$, 4-month: $8.7 \pm 1.9$, 8-month: $8.6 \pm 2.1$, and 12 -month: $8.7 \pm 1.7 \%$ ), while in the control group it appeared to increase at 8 months and return to baseline at 12 months (baseline: 9.2 \pm 2.1 , 4-month: $9.3 \pm 2.1$, 8-month: $9.5 \pm 2.3$, and 12-month: $9.2 \pm 2.2 \%$ ), but no statistically significant difference was detected in the univariate analysis (within-subjects p-value $=0.727$ and between-groups p-value $=0.062$ ). A multivariate model was constructed with two pre-specified co-variables, baseline HbAlc and end-of-study diabetes mellitus medication (insulin/ $\mathrm{kg} /$ day at 12 months was selected because no changes were observed in other glucose-lowering medications), and a difference in $\mathrm{HbAlc}$ between groups became evident (within-subjects $\mathrm{p}<0.001$ and between-groups $\mathrm{p}=0.044$ ).

Table 2 shows variations in other clinical and laboratory parameters after the intervention. A reduction was observed in systolic blood pressure (intervention: $-6 \mathrm{mmHg}$; controls $-8 \mathrm{mmHg}$ ) and diastolic blood pressure (intervention: $-2 \mathrm{mmHg}$; controls: $-7 \mathrm{mmHg}$ ), but there were no significant differences between groups. A comparable decrease in BMI was also observed in both groups. There was no correlation between BMI and blood pressure changes (systolic: $\mathrm{r}=-0.04, \mathrm{p}=0.595$; diastolic: $\mathrm{r}=0.04, \mathrm{p}=0.652$ ). Lipid profile varied during the study, but did not show a pattern indicating improvement or worsening, and was comparable in the two groups.

A benefit from the intervention was a reduction in distress associated with diabetes mellitus; patients participating in the structured course had a larger decrease in the PAID score in 12 months when compared to baseline (intervention: $-34 \pm 22$ vs. controls: $-26 \pm 18, \mathrm{p}=0.017$ ). Levels of physical inactivity between the inter- 
Figure 2

Diabetes knowledge score (2a) and $\mathrm{HbA} 1 \mathrm{c}(2 \mathrm{~b})$ in the intervention group (dashed black line) and control group (solid gray line). In $2 a, p<0.01$ for differences between groups. In $2 b, p=0.044$. For differences between groups after adjustments for $\mathrm{HbA} 1 \mathrm{c}$ at baseline and insulin dosage at the end of the study.

2a)

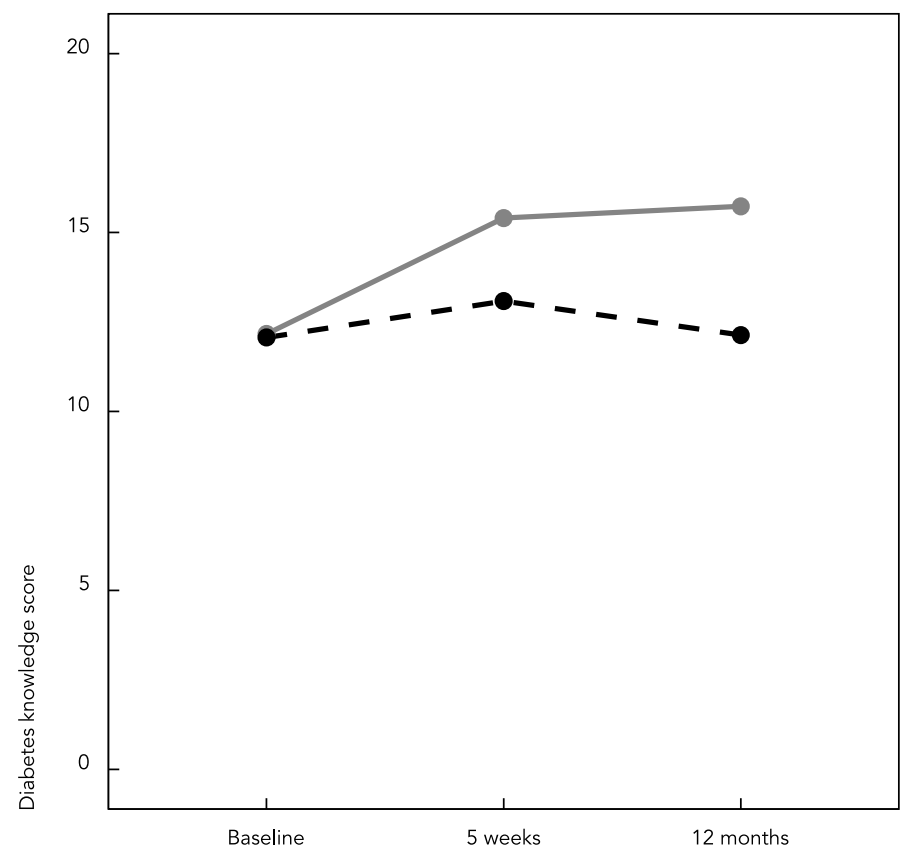

- - Intervention

- Control

2b)

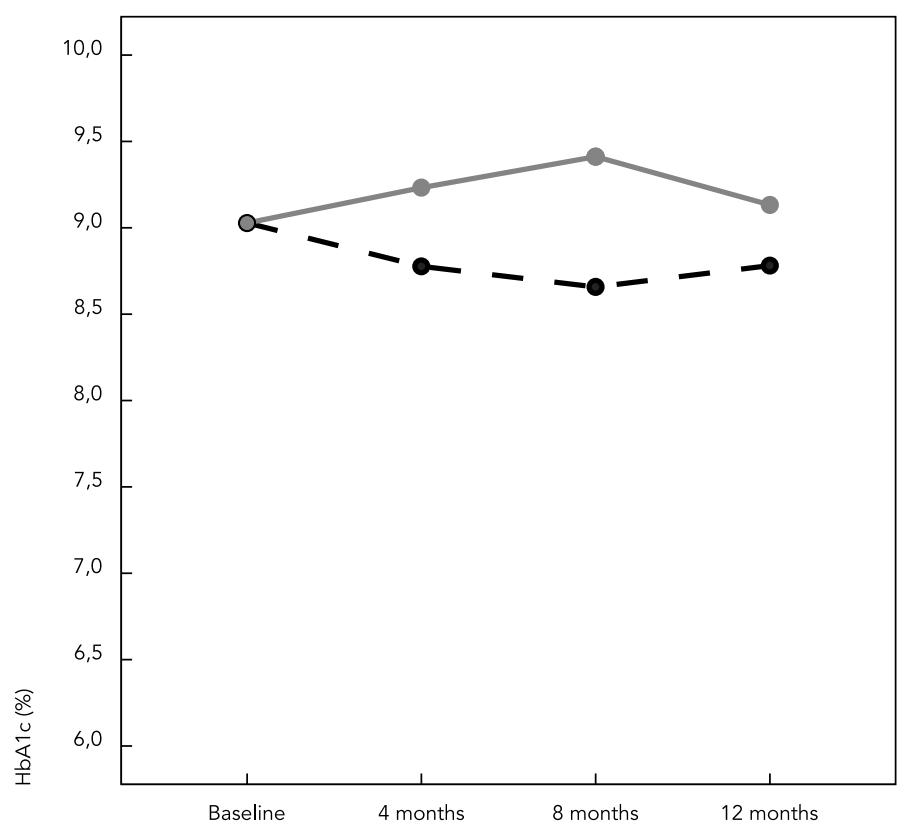

- - Intervention

Control 
Variations in clinical and laboratory parameters during the follow-up in the intervention and control groups.

\begin{tabular}{|c|c|c|c|c|c|c|}
\hline & \multirow[t]{2}{*}{ Baseline } & \multirow[t]{2}{*}{ 4-month } & \multirow[t]{2}{*}{ 8-month } & \multirow[t]{2}{*}{ 12-month } & \multicolumn{2}{|c|}{ p-value } \\
\hline & & & & & Within subject & Between groups \\
\hline \multicolumn{7}{|l|}{$\mathrm{BMI}[$ mean $\pm \mathrm{SD}]$} \\
\hline Intervention & $30.7 \pm 5.7$ & $30.2 \pm 5.3$ & $30.3 \pm 5.6$ & $30.4 \pm 6.3$ & $<0.01$ & 319 \\
\hline Control & $29.9 \pm 5.8$ & $29.9 \pm 5.9$ & $30.0 \pm 5.8$ & $30.1 \pm 6.2$ & & \\
\hline \multicolumn{7}{|c|}{ Waist circumference $[$ mean $\pm S D]$} \\
\hline Intervention & $105.0 \pm 13.0$ & $104.2 \pm 13.7$ & $104.1 \pm 13.3$ & $103.9 \pm 13.6$ & 913 & 1 \\
\hline Control & $103.4 \pm 12.3$ & $104.3 \pm 12.9$ & $104.2 \pm 13.0$ & $105.2 \pm 13.5$ & & \\
\hline \multicolumn{7}{|c|}{ Systolic blood pressure [mean \pm SD] } \\
\hline Intervention & $141 \pm 19$ & $135 \pm 18$ & $133 \pm 20$ & $135 \pm 18$ & $<0.001$ & 319 \\
\hline Control & $141 \pm 18$ & $131 \pm 19$ & $131 \pm 21$ & $133 \pm 20$ & & \\
\hline \multicolumn{7}{|c|}{ Diastolic blood pressure [mean \pm SD] } \\
\hline Intervention & $81 \pm 12$ & $77 \pm 13$ & $77 \pm 13$ & $79 \pm 11$ & $<0.001$ & 98 \\
\hline Control & $81 \pm 11$ & $76 \pm 13$ & $75 \pm 13$ & $74 \pm 14$ & & \\
\hline \multicolumn{7}{|c|}{ Cholesterol [mean \pm SD] } \\
\hline Intervention & $186 \pm 44$ & $188 \pm 41$ & $184 \pm 44$ & $188 \pm 51$ & $<0.001$ & 482 \\
\hline Control & $186 \pm 42$ & $181 \pm 31$ & $184 \pm 37$ & $183 \pm 38$ & & \\
\hline \multicolumn{7}{|c|}{$\mathrm{HDL}-\mathrm{c}[$ mean $\pm \mathrm{SD}]$} \\
\hline Intervention & $43 \pm 12$ & $45 \pm 12$ & $45 \pm 16$ & $43 \pm 12$ & $<0.001$ & 162 \\
\hline Control & $48 \pm 16$ & $47 \pm 15$ & $45 \pm 14$ & $45 \pm 14$ & & \\
\hline \multicolumn{7}{|c|}{ LDL-c [mean \pm SD $]$} \\
\hline Intervention & $108 \pm 37$ & $110 \pm 36$ & $102 \pm 33$ & $108 \pm 40$ & $<0.001$ & 489 \\
\hline Control & $105 \pm 34$ & $104 \pm 26$ & $106 \pm 31$ & $107 \pm 28$ & & \\
\hline \multicolumn{7}{|c|}{ Triglycerides [median (interquartile } \\
\hline \multicolumn{7}{|c|}{ interval)] } \\
\hline Intervention & $150(118-217)$ & $150(107-201)$ & $159(109-221)$ & $161(98-200)$ & $<0.001$ & 570 \\
\hline Control & $167(102-206)$ & $130(94-200)$ & $141(98-214)$ & $136(100-203)$ & & \\
\hline
\end{tabular}

BMI: body mass index; SD: standard deviation.

vention and control groups did not vary during the evaluation period: baseline $-83.6 \%$ vs. $88.3 \%$ ( $\mathrm{p}=0.61) ; 4$ months $-76.1 \%$ vs. $88.3 \%(\mathrm{p}=0.11) ;$ 8 months $-77.6 \%$ vs. $88.3 \%(\mathrm{p}=0.16)$; and 12 months $-83.6 \%$ vs. $86.7 \%(\mathrm{p}=0.80)$.

\section{Discussion}

In this sample of type 2 diabetes mellitus patients attending a primary care unit, a structured group education program improved patients' knowledge related to diabetes mellitus. HbAlc was similar between groups during the trial, but the intervention prevented an elevation in HbAlc during a 12-month follow-up after adjusting for baseline HbAlc and end-of-study insulin dose. The other observed benefit was improvement in distress associated with diabetes mellitus.
Our group had reported similar results in a previous study ${ }^{9}$. The current study was able to show that this approach was effective, regardless of the group (well-controlled not on insulin vs. uncontrolled, including insulin users), health care setting (primary vs. tertiary care), or the type of diabetes mellitus educator in charge (CDE vs. trained primary care generalist nurse). However, it should be noted that the intervention did not decrease HbAlc, but only prevented its elevation. Furthermore, the benefit was only evident after adjusting for baseline $\mathrm{HbAlc}$ and end-of-trial insulin dose.

A systematic review and meta-analysis has shown a larger effect of a group-based education program (-1.4\% in HbAlc in 4-6 months) 15 . However, the review included both randomized controlled and non-randomized trials. A subsequent meta-analysis 7 compared group versus 
individualized education; no differences were found between the two approaches, but the observed effect of both interventions was much smaller $(-0.3 \%$ in HbAlc) and was only seen in patients with baseline $\mathrm{HbAlc}>8 \%$. A recent randomized clinical trial 16 has questioned the benefit of group diabetes mellitus education. Group education decreased HbAlc by $0.27 \%$, which was comparable with the reduction observed in the control group $(-0.24 \%, \mathrm{p}=0.83)$ and lower than the reduction attributed to individualized education $(-0.51 \%, \mathrm{p}=0.01)$. However, patients allocated to the group education arm were less likely to complete the course and the diabetes mellitus educators were not completely familiar with the specific diabetes mellitus course utilized, which could explain the lack of effect of group education.

Based on our previous experience with diabetes mellitus education trials and the available literature 15,16,17,18, we expected HbAlc to decrease after the intervention. However, the differences in $\mathrm{HbAlc}$ between the groups in the current study were due to stabilization of values in the intervention group and an increase in controls. Since diabetes mellitus is a progressive disease, the control group represents the usual clinical course of the disease, whereas HbAlc deterioration was prevented by the educational intervention. The benefit of diabetes mellitus only became evident after adjusting for confounding. Baseline HbAlc is a well-known determinant of its own variation after interventions, which justifies this variable's inclusion in the multivariate model 19 . We also consider that adjusting for medication changes was important, since the study had a long followup, and primary care physicians were encouraged to modify patients' medications as necessary. We decided to include only insulin in the final model because no modification in the oral medications was observed during the trial.

Decreases in blood pressure and BMI were similar in the two groups, which can be attributed to participation in a study. It is well-known that subjects are more motivated when they are being observed or when some interest is shown in them 20 . Since the entire primary care unit was involved, it might have been motivated to improve patients' outcomes, given the presence of an ongoing clinical trial.

Notably, one of the intervention meetings was reserved to discuss non-pharmacological interventions - diet and exercise - with emphasis on weight reduction in the case of overweight and obese subjects. Although a reduction in BMI was observed in both groups, it was quite small (intervention: $-0.3 \mathrm{~kg} / \mathrm{m}^{2}$; controls: $-0.1 \mathrm{~kg}$ / $\mathrm{m}^{2}$ ). Since weight reduction is an important part of type 2 diabetes mellitus treatment, we consider that a more effective approach focusing weigh reduction should be incorporated in diabetes mellitus group education. A possible model to be implemented is the one used by Weight Watchers, associated with a significant weight reduction compared to standard care in non-diabetic obese patients attending primary care units 21 . Importantly, no improvement was seen in physical activity. More emphasis on this issue should probably have been incorporated during meetings.

The main potential limitation to this study was the care provided to the control group. Both the intervention and control groups visited the primary care unit and contacted the same nurse educator with identical frequency, and were allowed to ask questions about diabetes mellitus, which were answered with concise and objective information in order to avoid turning simple questions into educational sessions. Although the control group's knowledge about diabetes mellitus increased during the trial to a lesser degree than in the intervention group, it may have influenced the results. This may have been a conservative bias, since the control group may have received some informal education on diabetes. The decreases in blood pressure and BMI in both groups may represent a sign of knowledge "contamination" in the control group. The results also support the idea that structured educational interventions are associated with better outcomes than open-ended models. Another possible limitation involved the exclusion criteria, which could limit the results' extrapolation to patients with those characteristics.

\section{Conclusion}

In conclusion, a structured educational course delivered in group format is a useful tool to improve knowledge and distress related to diabetes, as well as to prevent progressive increases in HbAlc in type 2 diabetes mellitus patients attending a primary care unit. As attested by improvements in blood pressure and BMI in both groups educational activities in a health care unit can create an atmosphere that favors patients' adherence to clinical treatment and healthy habits. 


\section{Contributors}

M. F. F. Grillo participated in the study's design and coordination, administered the educational course, performed the statistical analysis, and drafted the manuscript. C. R. Neumann, S. F. Scain and J. L. Gross participated in the study design and helped draft the manuscript. R. F. Rozeno administered the educational course and helped draft the manuscript. L. Beloli and T. Perinetto participated in the data collection helped draft the manuscript. C. B. Leitão participated in the study design, performed the statistical analysis, and helped draft the manuscript.

\section{Acknowledgments}

The authors wish to thank the health care professionals and patients of the Santa Cecília Primary Care Unit/ Hospital de Clínicas de Porto Alegre (HCPA) in Porto Alegre, Brazil, for their support during this research. This study was supported by Fundo de Incentivo à Pesquisa (FIPE) do HCPA.

\section{Conflicts of interest}

The authors have no conflicts of interest to disclose.

\section{References}

1. Scheffel RS, Bortolanza D, Weber CS, Canani LH, Costa LA, Santos KG. Prevalence of micro and macroangiopathic chronic complications and their risk factors in the care of outpatients with type 2 diabetes mellitus. Rev Assoc Med Bras 2004; 50:263-7.

2. Stratton IM, Adler AI, Neil HAW, Matthews DR, Manley SE, Cull CA, et al. Association of glycaemia with macrovascular and microvascular complications of type 2 diabetes (UKPDS 35): prospective observational study. BMJ 2000; 321:405-12.

3. Sociedade Brasileira de Diabetes. Diretrizes da Sociedade Brasileira de Diabetes. 3a Ed. Itapevi: A. Araújo Silva Farmacêutica; 2009

4. Renders CM, Valk GD, Franse LV, Schellevis FG, van Eijk JTM, van der Wal G. Long-term effectiveness of a quality improvement program for patients with type 2 diabetes in general practice. Diabetes Care 2001; 24:1365-70.

5. Powers MA, Bardsley J, Cypress M, Duker P, Funnel MM, Fishl AH, et al. Diabetes self-management education and support in type 2 diabetes: a joint position statement of the American Diabetes Association, the American Association of Diabetes Educators, and the Academy of Nutrition and Dietetics. Diabetes Care 2015; doi: 10.2337/dc15-0730.

6. Standards of medical care in diabetes 2015. Diabetes Care 2015; 38 Suppl:S1-94.

7. Duke S, Colagiuri S, Colagiuri R. Individual patient education for people with type 2 diabetes mellitus. Cochrane Database Syst Rev 2009; 1(1):CD005268.

8. Gagliardino JJ, Etchegoyen G. A model educational program for people with type 2 diabetes. Diabetes Care 2001; 24:1001-7.
9. Scain SF, Friedman R, Gross JL. A structured educational program improves metabolic control in patients with type 2 diabetes. Diabetes Educ 2009; 35:603-11.

10. Matsudo S, Araújo T, Marsudo V, Andrade D, Andrade E. Questionário internacional de atividade física (IPAQ): estudo de validade e reprodutibilidade no Brasil. Rev Bras Ativ Fís Saúde 2001; 6:5-18.

11. Gross CC, Scain SF, Scheffel R, Gross JL, Hutz CS. Brazilian version of the problem areas in diabetes scale (B-PAID): validation and identification of individuals at high risk for emotional distress. Diabetes Res Clin Pract 2007; 76:455-9.

12. Trinder P. Determination of blood glucose using an oxidase-peroxidase system with a non-carcinogenic chromogen. J Clin Pathol 1969; 22:158-61.

13. Reichard P, Nilsson B-Y, Rosenqvist U. The effect of long-term intensified insulin treatment on the development of microvascular complications of diabetes mellitus. N Engl J Med 1993; 329:304-9.

14. Friedewald WT, Levy RI, Fredrickson DS. Estimation of the concentration of low-density lipoprotein cholesterol in plasma, without use of the preparative ultracentrifuge. Clin Chem 1972; 18: 499-502.

15. Deakin T, McShane CE, Cade JE, Williams RD. Group based training for self-management strategies in people with type 2 diabetes mellitus. Cochrane Database Syst Rev 2005; (2):CD003417.

16. Sperl-Hillen J, Beaton S, Fernandes O, Worley AV, Benitez GV, Parker E. Comparative effectiveness of patient education methods for type 2 diabetes: a randomized controlled trial. Arch Intern Med 2011; 171:2001-10. 
17. Shojania KG, Ranji SR, McDonald KM, Grimshaw JM, Sundaram V, Rushakoff RJ, et al. Effects of quality improvement strategies for type 2 diabetes on glycemic control. JAMA 2006; 296:427-40.

18. Norris SL, Lau J, Smith SJ, Schmid CH, Engelgau MM. Self-management education for adults with type 2 diabetes. Diabetes Care 2002; 25:1159-71.

19. Sherifali D, Nerenberg K, Pullenayegum E, Cheng JE, Gerstein HC. The effect of oral antidiabetic agents on A1C levels. Diabetes Care 2010; 33: 1859-64.

\section{Resumo}

O objetivo deste estudo foi avaliar o efeito de um programa de educação estruturado em grupo, aplicado por enfermeira de cuidados primários a pacientes com diabetes mellitus tipo 2. A amostra contou com 137 pacientes com diabetes mellitus tipo 2, randomizados em dois grupos: intervenção, (curso educativo de cinco semanas e reforços a cada 4 meses, durante um ano) e grupo controle (sem educação estruturada) com avaliação do controle metabólico, peso, pressão arterial, escores de estresse e conhecimento relacionados ao diabetes. Não houve diferenças entre os grupos na HbAlc em 4, 8 ou 12 meses, quando comparado aos valores basais. Foi observado um incremento na $\mathrm{HbAlc}$ no grupo controle após ajustes para HbAlc no basal e dose de insulina ( $p=0,044$ entre grupos). Os escores de conhecimento e estresse relacionados ao diabetes melhoraram após a intervenção. Um programa educacional estruturado ministrado à pacientes com diabetes mellitus tipo 2 atendidos em atenção primaria melhorou o conhecimento e estresse associados à doença. Além disso, nossos resultados sugerem uma prevenção de elevação da HbAlc.

Diabetes Mellitus; Educação em Saúde; Atenção Primária à Saúde
20. Braunholtz DA, Edwards SJL, Lilford RJ. Are randomized clinical trials good for us (in the short term)? Evidence for a "trial effect". J Clin Epidemiol 2001; 54:217-24.

21. Jebb SA, Ahern AL, Olson AD, Aston LM, Holzapfel C, Stoll J, et al. Primary care referral to a commercial provider for weight loss treatment versus standard care: a randomised controlled trial. Lancet 2011; 378:1485-92.

\section{Resumen}

El objetivo de este estudio fue evaluar el efecto de un programa de educación estructurada en grupo, aplicado por la enfermera de atención primaria para pacientes con diabetes mellitus tipo 2. La muestra incluyó a 137 pacientes con diabetes mellitus tipo 2, aleatorizados en dos grupos: intervención (curso de formación de 5 semanas, com refuerzos cada 4 meses durante un año) y el grupo de control (sin educación estructurada) para evaluar el control metabólico, peso, presión arterial, niveles de estrés y conocimientos relacionados con la diabetes. No hubo diferencias entre los grupos en HbAlc en 4, 8 ó 12 meses en comparación con los valores basales. Se observó un aumento de HbAlc en el grupo de control después del ajuste de HbAlc en la linea de base y a la dosis de la insulina ( $p=0,044$ entre grupos). Las puntuaciones de los conocimientos y del estrés relacionadas con la diabetes mejoraron después de la intervención. Un programa educativo estructurado ofrecido a los pacientes con diabetes mellitus tipo 2 tratados en la atención primaria mejoró el conocimiento y el estrés asociado con la enfermedad. Por otra parte, nuestros resultados sugieren una prevención elevada de la HbAlc.

Diabetes Mellitus; Educación en Salud; Atención Primaria de Salud
Submitted on $22 /$ Jun/2015

Final version resubmitted on $04 / \mathrm{Feb} / 2016$

Approved on 02/Mar/2016 